\title{
Magnetotelluric Soundings of the Source Area of the 1999 Chi-Chi Earthquake in Taiwan: Evidence of Fluids at the Hypocenter
}

\author{
Chow-Son Chen ${ }^{1, *}$ and Chien-Chih Chen ${ }^{2}$ \\ (Manuscript received 28 February 2000, in final form 20 May 2000)
}

\begin{abstract}
Magnetotelluric (MT) Soundings were used as part of an integrated project to map the earthquake-bearing structures in the Chi-Chi earth quake source area as soon as possible after the 21 September 1999, magnitude 7.3, Chi-Chi earthquake in Taiwan. Seventeen MT soundings were conducted and analyzed to map $2 \mathrm{D}$ resistivity distributions. Results show a low resistivity anomaly, less than $10 \mathrm{ohm}-\mathrm{m}$, with depth ranging about 10$15 \mathrm{~km}$ below the hypocenter of the earthquake. Based on the temperature estimates from the MT resistivities, it is inferred that the main cause of this low resistivity zone is not related to high temperature, but rather to the presence of fluids in the crust. Although a localized shear stress concentration provoked by the tectonic escape process in the region might be used to explain the mechanism of the Chi-Chi earthquake, this study, which correlates the resistivity model with aftershock seismicity, raises the important possibility that the fluids released though metamorphic dehydration may have been one of the most important causes of the Chi-Chi earthquake.
\end{abstract}

(Key words: The Chi-Chi earthquake, The Chelungpu fault, MT, Electrical structures, Dehydration, Earthquake nucleation zone)

\section{INTRODUCTION}

On 21 September, 1999, at 01:47 local time, i.e., at 1747:15.79 UT on 20 September, the largest earthquake of the century $\left(\mathrm{M}_{\mathrm{L}} 7.3\right)$ occurred "suddenly and without foreshock activity" in central Taiwan. Its epicenter $\left(23.85^{\circ} \mathrm{N}, 120.82^{\circ} \mathrm{E}\right)$ was located near the town of ChiChi from which the earthquake received its name. The depth of the Chi-Chi hypocenter was about $7 \mathrm{~km}$. There was an extensive surface rupture about $85 \mathrm{~km}$ in total along the Chelungpu (CLP) fault with vertical thrust and left lateral strike-slip offsets. The maximum displacement

\footnotetext{
${ }^{1}$ Institute of Geophysics, National Central University, Chung-Li, Taiwan , ROC

${ }^{2}$ Institute of Earth Sciences, Academia Sinica, Nankang, Taipei, Taiwan, ROC

${ }^{\star}$ Corresponding author address: Prof. Chow-Son Chen, Institute of Geophysics, National Central University, Chung-Li, 320 Taiwan, ROC; E-mail: chusen@sal.gep.ncu.edu.tw
} 
of about 9.8 meters is among the largest fault movements thus far measured for earthquakes in recent times (Ma et al. 1999). There was severe destruction in central Taiwan with over 2300 fatalities and 8700 injuries. Fortunately, the Taiwan Earthquake Early Warning System (Wu et al. 1999) operated by the Central Weather Bureau Seismological Center reported the earthquake's location, magnitude and intensity distribution within two minutes; this quick broadcast of information enabled a fast emergency response by the government.

Tectonically, Taiwan is located in a complex, active region. The Philippine Sea plate subducts northwestward along the Ryukyu trench in the north and the Eurasian plate underthrusts the Philippine Sea plate along the Manila trench in the south (Fig 1). The Philippine Sea plate moves northwestward at the rate of approximately $8 \mathrm{~cm} / \mathrm{yr}$ relative to the Eurasian plate (Yu et al. 1997), creating the Taiwan collision zone. This high tectonic stress in the Taiwan collision zone is the main cause of this historical large earthquake on the small island of Taiwan.

A localized shear stress concentration provoked by the tectonic escape process in the region might be used to explain the possible mechanism of earthquakes in the foreland belt of central-western Taiwan. However, there have been numerous reports in recent years of possible overpressure fluids inducing earthquakes (Zhao et al. 1992; Ague et al. 1998). We began to conduct an investigation into the geoelectric structure in the Chi-Chi earthquake source area as soon as possible after the earthquake to better understand what may have triggered this earthquake and how the rupture proceeded after initiation. As we will now describe, the ChiChi earthquake nucleation zones had a low resistivity anomaly, which suggests the existence of overpressurized fluids and raises the important possibility that metamorphic dehydration may have been an important cause of the Chi-Chi earthquake.

\section{METHOD}

To map the deep resistivity structure of the Chi-Chi earthquake source area, a tensor MT survey was carried out. V5-MT (Phoenix Geophysics, Canada) with a capability of measuring the broad band range of 384 to $0.00055 \mathrm{~Hz}$ was used. For acquire an MT sounding, measurements were made using five field components including two electric fields $\left(\mathrm{E}_{\mathrm{x}}\right.$ and $\left.\mathrm{E}_{\mathrm{y}}\right)$ and three magnetic fields $\left(\mathrm{H}_{x}, \mathrm{H}_{y}\right.$ and $\left.\mathrm{H}_{z}\right)$. Seventeen MT soundings were conducted around the region of the epicenter of the Chi-Chi earthquake (Fig. 1).

The tensor MT survey obtained two orthogonal apparent resistivities and the associated phase angle. In the 2D earth structure, $\rho_{x y}$ and $\phi_{x y}$ are referred to as the TE mode (or Epolarization, which is actually or parallel to the strike), and $\rho_{\mathrm{yx}}$ and $\phi_{\mathrm{yx}}$ the TM mode (or Bpolarization). Figures $2 \mathrm{a}$ and $2 \mathrm{~b}$ show the apparent resistivity and the phase angle for each site along profile AA', respectively. It is worth noting that the phase angle plot can greatly assist in the assessment of the MT data quality of each sounding; the smoothed phase data suggest that the experimental signal to noise ratio is quite satisfactory since phase is relatively sensitive to noise disturbances.

For a quantitative evaluation of the subsurface geoelectric section, the Occam's inversion (Constable et al. 1987), which produces a model that is maximally smooth in resistivity struc- 


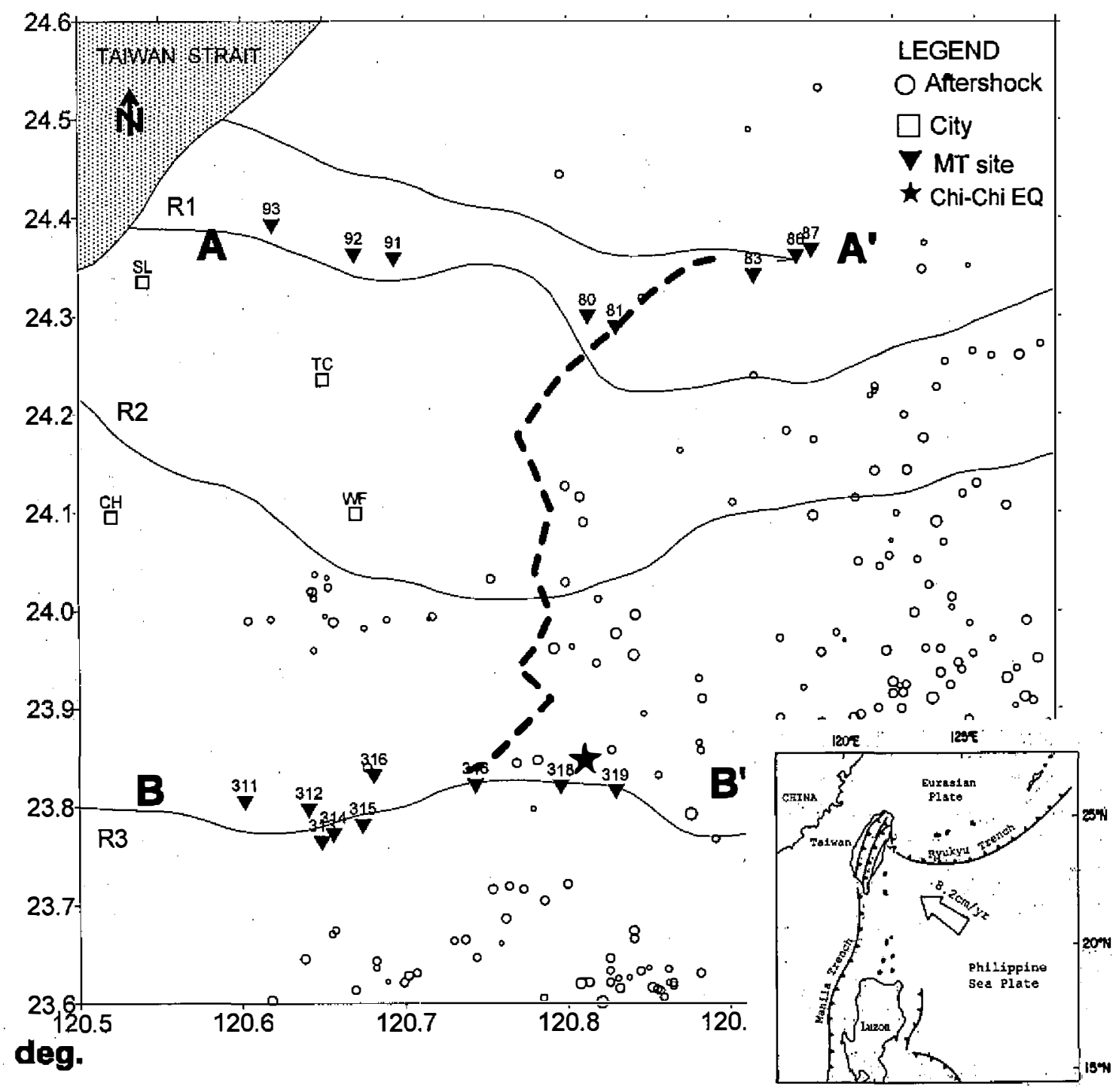

Fig. 1. Locations of MT soundings of this study are indicated by inverted triangles and their interpretation profiles are indicated by $\mathrm{AA}^{\prime}$ ' and BB'. The asterisk indicates the epicenter of the 1999 Chi-Chi, Taiwan earthquake, and the aftershocks with magnitude between 4 and 7 are indicated by open circles. The bold dashed line indicates the Chelungpu fault; the fault trace was ruptured during this earthquake. Most of the large aftershocks occurred east of the Chelungpu fault. The inset shows the tectonic setting in the Taiwan region and the vector of relative motion between the Philippine Sea plate and the Eurasian plate is shown by the arrow. R1=Tacha River; R2=Wuhsi River; R3=Hsilo River; TC=Taichung City; WF=Wufeng City; $\mathrm{CH}=$ Changhua City; $\mathrm{SL}=$ Shalu City. 
(a)
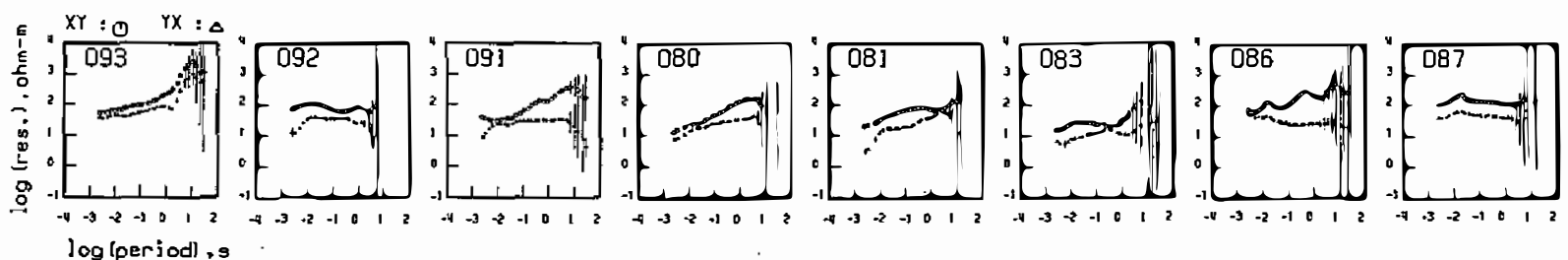

(b)
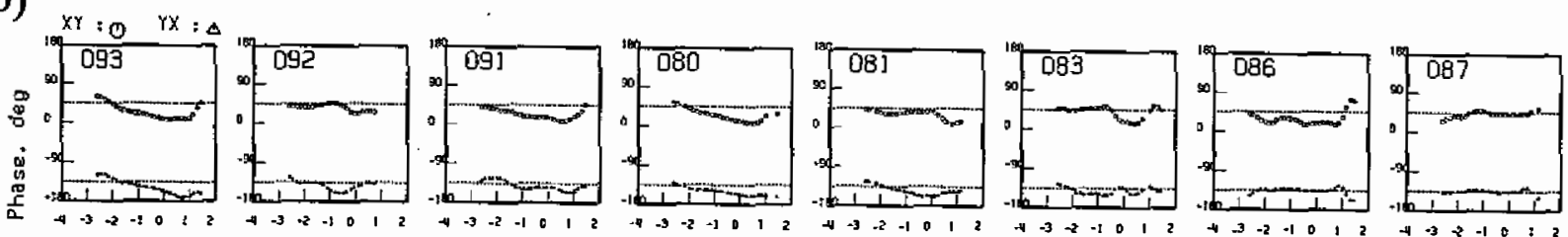

log (period) ss

(c)

\section{$\leftarrow$ CLP fault $\rightarrow$}
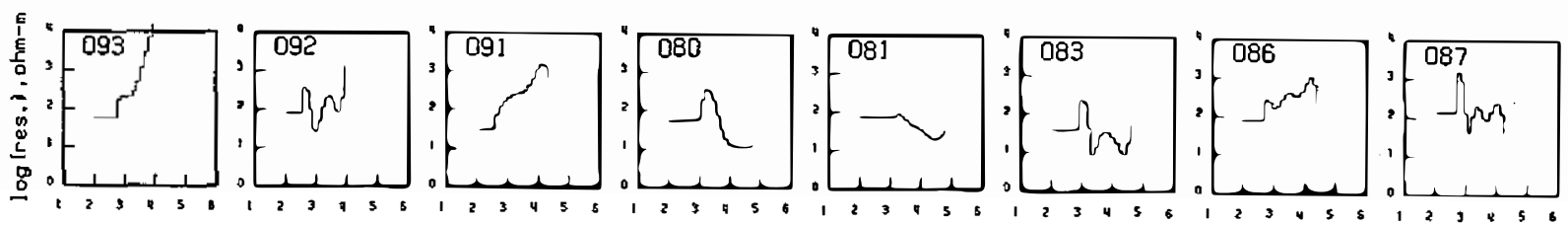

log (depthi .n

Fig. 2. (a) Apparent resistivities, (b) phases and (c) Occam's inversions of profile AA' are indicated as shown in Fig. 1. The horizontal scale is $\log _{10}$ (period) in seconds for (a) and (b). The vertical scale for the apparent resistivity is $\log _{10}$ (resistivity) in ohm-m; that for phase is in degrees. The TE (xy) and TM (yx) modes are indicated by circles and triangles, respectively. Two dotted lines, indicating $45^{\circ}$ and $-135^{\circ}$, are superimposed on each phase plot to show the half-space response. Occam's inversions (c) show resistivities versus depth of each sounding. The vertical scale is $\log _{10}$ (resistivity) in ohm-m, while the horizontal scale $\log _{10}$ (depth) is in meters. Note that the low resistivity anomaly at sounding 081 is the location of the Chelungpu (CLP) fault zone; soundings on both sides of the CLP fault zone, 080 and 083, were also affected producing about a low resistivity. 
ture, was used to produce the 1D model for each set of sounding data. The reasons for employing the Occam's inversion are: (1) the results of the Occam's inversion are very similar to a highly smoothed resistivity log and therefore easily understood, especially in the reconnaissance stage, and (2) there is no need to preset an initial model for the Occam's inversion, and the inversion results are unique. Because $\rho_{x y}$ is less affected by lateral inhomogenety than $\rho_{\mathrm{yx}}, \rho_{\mathrm{xy}}$ was selected for 1D inversion. The Occam's inversion of each sounding along profile $\mathrm{AA}^{\mathrm{xy}}$ is shown in Fig. 2c. Two findings are of particular interest: (1) although the MT soundings resolved the depths from at least $200 \mathrm{~m}$ (\#092, \#091 and \#087 etc.) to more than $60 \mathrm{~km}$ (\#080 and \#081, etc.), due to the instrumentation bandwidth 384 to $0.00055 \mathrm{~Hz}$ and geoelectrical structures of the sounding locations, better interpretations are most likely limited to the range of $1 \mathrm{~km}-20 \mathrm{~km}$. (2) an interesting feature is a distinct low resistivity anomaly at sounding 081 which is the location of the CLP fault zone. Soundings on both sides of the CLP fault zone, 080 and 083 , were also affected by the disturbances of the CLP fault which made them produce a low resistivity anomaly.

In order to assess the subsurface 2D resistivity structures of the Chi-Chi earthquake source area quantitatively, two W-E profiles, $\mathrm{AA}^{\prime}$ and BB', were constructed (Fig. 3).

\section{RESULTS}

First consider profile BB' (Fig. 3b) which crosses the Chi-Chi epicentral zone. The most significant feature obtained by means of MT is the existence of a distinct low resistivity anomaly (LRA), less than $10 \mathrm{ohm}-\mathrm{m}$, with depths ranging about $10-15 \mathrm{~km}$ that extends laterally $5 \mathrm{~km}$ beneath the hypocenter of the Chi-Chi earthquake. Two other features in profile BB' are noteworthy evident. First, large resistivity discontinuity was revealed in the CLP fault zone (Fig. 3b). The MT imaged the CLP fault as a zone of medium resistivity ( $100 \mathrm{ohm}-\mathrm{m})$ from the surface to a depth of $20 \mathrm{~km}$ with a dip gently to the west, different from the common geologic viewpoint which indicates dipping to the east. The fact is the electrical structure better reflects the fluids in the crust than the geologic structure itself. More details are discussed in the next section. Secondly, the western end of the profile (sounding 311 ) shows that a low resistivity anomaly might be associated with the soft and thick alluvial sediments that have a high water content.

Profile AA' (Fig. 3b) is about $40 \mathrm{~km}$ north of profile BB' and also passes through the CLP fault zone. Generally speaking, the geoelectric patterns of profile $\mathrm{AA}^{\prime}$ ' is the northem extension of profile $\mathrm{BB}^{\prime}$, i.e., a low resistivity crust is on the eastern side of the profile and a high resistivity crust is on the western side with medium resistivity $(100 \mathrm{ohm}-\mathrm{m})$, reflecting the CLP fault zone, in between. Note that both profiles lie in the same geologic province of Taiwan, the Western Foothills, and are characterized by similar surface geological conditions; due to location difference (BB' passing through the epicentral zone while $\mathrm{AA}^{\prime}$ ' is far away from the epicentral zone), however, the profiles do not show the same order of the LRA. The presence of a shallow upper crustal conductor (LRA) located underneath the epicentral region (Fig. 3b) is clearly brought out. 
(a)

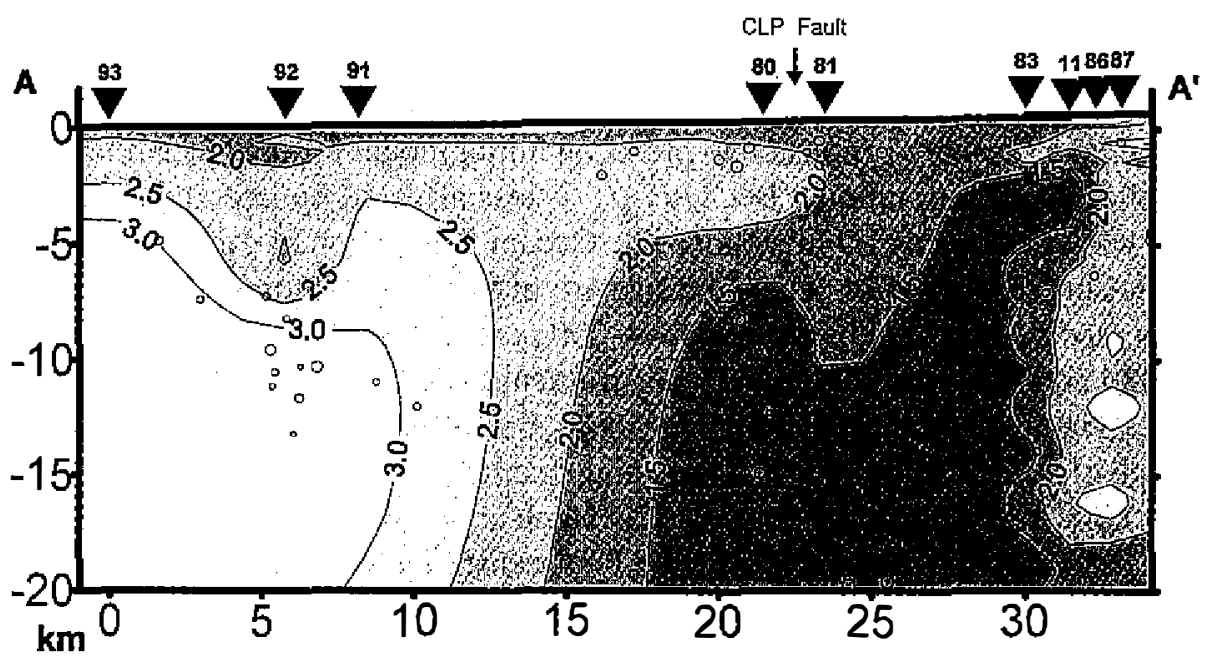

(b)

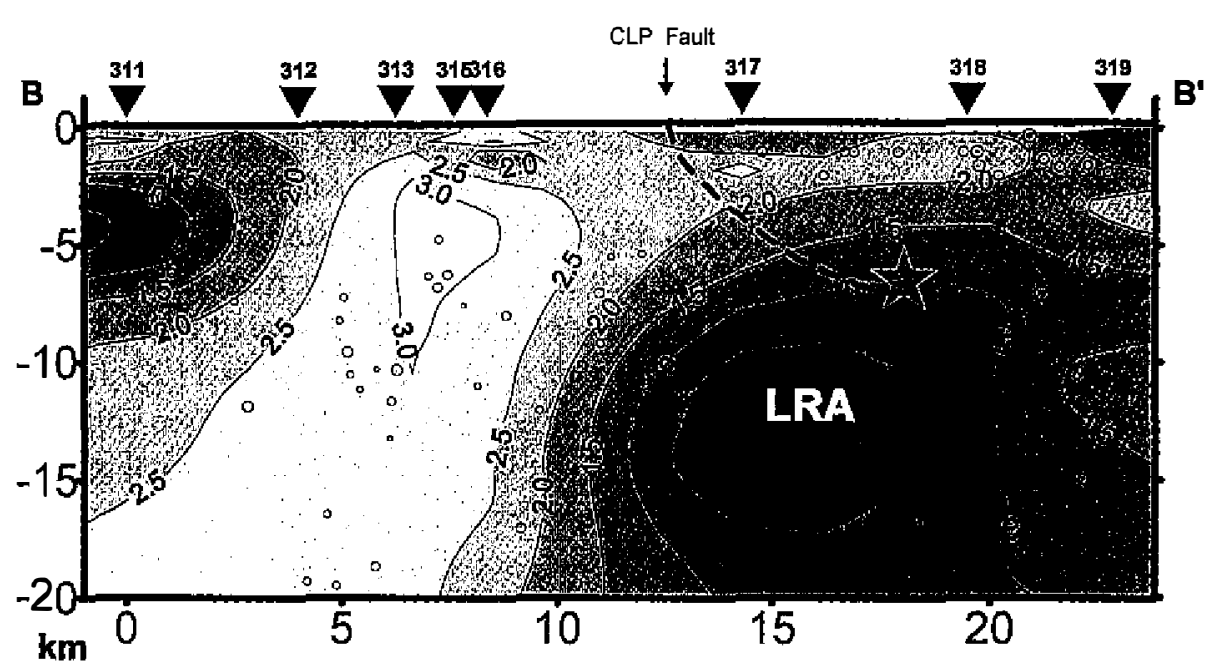

Fig. 3. Geoelectric sections along profile AA' (a) and profile BB' (b) are indicated as shown in Fig. 1. The inverted triangles on the surface topography indicate the sounding points. Resistivities, in $\log _{10}$ (resistivity) ohm$\mathrm{m}$, are contoured with values the lower the darker. The asterisk indicates the epicenter of the 1999 Chi-Chi earthquake in Taiwan, and the aftershocks with magnitude between 1 and 7 are indicated by open circles. The most significant feature in (b) is the existence of a distinct low resistivity anomaly (LRA) beneath the hypocenter of the Chi-Chi earthquake which was caused by fluids. Most of the large aftershocks occurred above the LRA and east of the CLP fault. 


\section{DISCUSSION}

A variety of factors could result in high electrical conductivity in the crust, e.g., fluids, carbon/graphite, partial melt, high temperature etc. (Jones 1987). For the purpose of verifying the assumption that the low resistivity in the uppercrust of the Chi-Chi area may possibly have its origin in enhanced temperature, the transformation of resistivity to the temperature was calculated (Fig. 4). The relationship between electrical conductivity and the temperature in rocks was discussed by Keller and Frischknecht (1966). Accordingly,

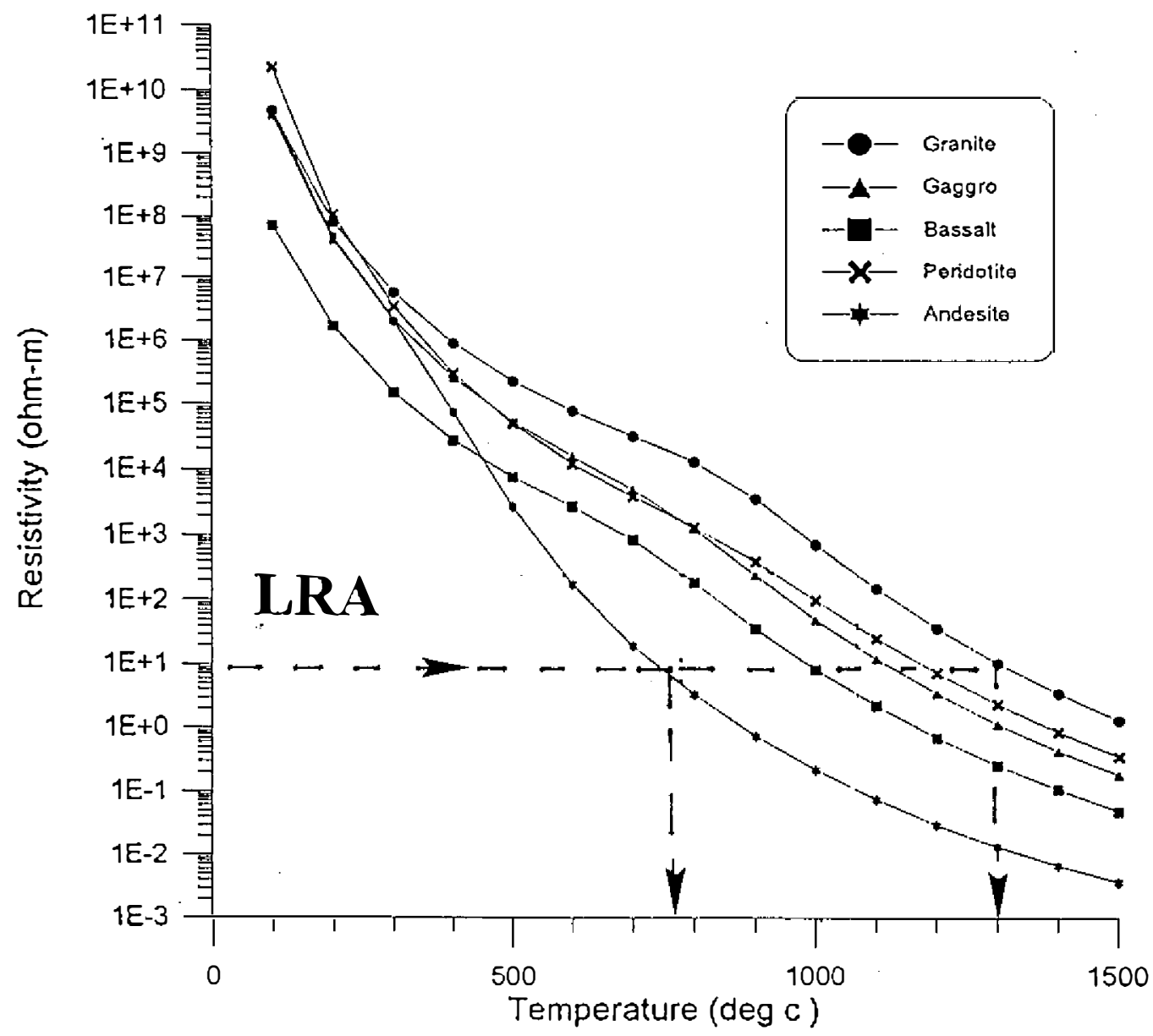

Fig. 4. Temperature estimates based on MT resistivities and rock types (Keller and Frischknecht 1966). If the LRA (low resistivity anomaly) beneath the Chi-Chi earthquake was caused by merely the enhanced temperature, the temperature should have been as high as $750-1300^{\circ} \mathrm{C}$. However, the rise in temperature beneath the Western foothills is far below this temperature range; thus, the most probable cause of the LRA is fluids. 


$$
\sigma=1 / \rho=A_{1} e^{-U_{1} / K T}+A_{2} e^{-U_{2} / K T},
$$

where $\mathrm{T}$ is absolute temperature; $\mathrm{k}$ is Boltzman's constant $\left(1.38 \times 10^{-3} \mathrm{ev} /{ }^{\circ} \mathrm{C}\right)$; parameters $A_{1}$ and $A_{2}$ are determined by the number of ions available for conduction and their mobility through the lattice; and $\mathrm{U}_{1}$ and $\mathrm{U}_{2}$ are the activation energies required to liberate these ions. Values for the parameters of a variety of rocks are given in Table 1. The relationship between resistivity and temperature was calculated and is plotted (Fig. 4). Broadly speaking, the higher the temperature, the lower the resistivity observed. In addition, different rock types just shift their curves along the resistivity axis, but their shapes mostly remain the same (except for andesite).

If the LRA beneath the Chi-Chi earthquake was caused by the enhanced temperature alone, the temperature should have been as high as $750-1300^{\circ} \mathrm{C}$. However, only an approximate $300^{\circ} \mathrm{C}$ or lower rise in temperature at the depth of $9 \mathrm{~km}$ beneath the Western foothills was reported, based on petroleum exploration (Suppe 1981). This temperature rise could not have been great enough to produce such a low resistivity anomaly. The detectable LRA in the upper crust beneath the Chi-Chi earthquake would have, therefore, required the presence of other factors.

Lithological heterogeneity in the crust could cause anomalies in resistivity, but it is subtle below $300^{\circ} \mathrm{C}$ (Fig. 4). The fact is that bulk resistivities from the surface to more than a $15-\mathrm{km}$ depth in a normal crust are controlled by aqueous electrolytic conduction by way of pores, fractures, faults and shear zones (Ward 1990). Due to the high sensitivity of electromagnetic exploration for fluids in rocks, we should ascribe the most probable cause of LRA to fluids or magma reservoirs. Near the Chi-Chi region there is no active volcano (Ho 1975). Therefore, we strongly suggest that the LRA in the Chi-Chi area be not related to a magma reservoir, but rather to the presence of fluids in the crust. One possibility for the origin of fluids is through the dehydration of the crust. This has previously been suggested as an explanation for the common occurrence of low resistivities in the continental crust (Jones 1987). Hyndman (1998) and Gough (1992) also pointed out that for areas that were reactivated in the Phanerozoic period, fluids might be the most likely cause of anomalously high conductivity.

The Chi-Chi area is located in transition from a thrust regime in the Central Range to an

Table 1. Parameters defining the temperature dependence of resistivity in solid electrolytes (Keller and Frischknecht, 1966).

\begin{tabular}{|lcccc|}
\hline Rock & A1 (s/cm) & A2 ( s/cm) & U1 (ev) & U2 (ev) \\
\hline Granite & $5 \mathrm{e}-4$ & le5 & 0.62 & 2.5 \\
\hline Gabbro & $7 \mathrm{e}-3$ & $1 \mathrm{e} 5$ & 0.70 & 2.2 \\
\hline Basalt & $7 \mathrm{e}-3$ & le5 & 0.57 & 2.0 \\
\hline Peridotitc & $4 \mathrm{e}-2$ & $1 \mathrm{e} 5$ & 0.81 & 2.3 \\
\hline Andesite & $6 \mathrm{e}-3$ & $1 \mathrm{e} 5$ & 0.70 & 1.6 \\
\hline
\end{tabular}


escape region toward the Western foothills in the foreland belt of central-western Taiwan. This localized shear stress concentration provoked by the tectonic escape process in the region may explain the mechanism of the Chi-Chi earthquake. In the meantime, the dehydration of metamorphic rocks may have taken place supplying the fluids and, consequently, reducing the resistivity of the rocks. If the permeability of the rocks in the reaction zone was low and kinetic reaction overstepping was important, then pore fluid pressure would be expected to increase rapidly in the reaction zone, the rock strength would decrease, and hydrofracture and fault rupture would then be possible. Ague et al. (1998) indicated that only a small volume of fluid is necessary to trigger a seismic event. Similar results have been reported for earthquake zones elsewhere (Gajewski et al. 1987; Gupta et al. 1996; Zhao et al. 1996). For example, Zhao et al. concluded that the LRA lies directly below the focal area where the strongest earthquake occurred in Kobe, Japan (1996).

\section{CONCLUSIONS}

This study correlates the resistivity model with the Chi-Chi earthquake-baring structures, raising the important possibility that the existence of a shallow fluid-filled zone in the upper crust below the hypocentral region may have been a possible cause of this earthquake. The low resistivity anomaly below the Chi-Chi hypocenter may have been due to overpressurized, fluid-filled, fractured rock matrix near the bottom of the seismogenic layer. The potential sources of these fluids may be dehydration of minerals, fluids trapped in pore spaces and meteoric water. In the Taiwan area, the subducted ocean crust on the top of the slab may also contribute to the accumulation of fluids in the crust. The existence of overpressurized fluids beneath the seismogenic layer may affect the long-term structural and compositional evolution of the fault zone, change its strength of the fault zone, thereby altering the local stress regime. These influences may have enhanced stress concentration in the seismogenic layer leading to mechanical failure, and in this case may have thus contributed to the nucleation of the Chi-Chi earthquake.

Future investigations using other geophysical methods, such as seismic tomography if could reveal low seismic velocity and high Poisson's ratio anomaly, would provide further constraints on this interpretation: the existence of a shallow fluid-filled zone in the upper crust below the Chi-Chi hypocentral region.

Acknowledgments This study was financially supported by the National Science Council of the Republic of China under grant NSC89-2116-M008-006, which is a three-year program of the study of the earthquake-bearing structures of Taiwan started in 1997.

\section{REFERENCES}

Ague, J. J., J. Park, and D. M. Rye, 1998: Regional metamorphic dehydration and seismic hazard. Geophys. Res. Letts., 25, 4221-4224.

Constable, S. C., R. L. Parker, and C. G. Constable, 1987: Occam's inversion: a practical 
algorithm for generating smooth models from electromagnetic sounding data. Geophysics, 52, 289-300.

Gajewski, D., W. S. Holbrook, and C. Prodehl, 1987: A three-dimensional crustal model of southwest Germany derived from seismic refraction data. Tctonophysics, 142, 49-70.

Gupta, H. K., S. V. S. Sarma, T. Harinarayana, and G. Virupakshi, 1996: Fluids below the hypocentral region of the Latur earthquake, India: Geophysical indicators. Geophys. Res. Letts., 23, 1569-1572.

Gough, D. L., 1992: Electromagnetic exploration for fluids in the earth's crust. Earth Sci. Rev., 32, 3-18.

Hyndman, R. D., 1998: Dipping seismic reflector, electrically conductive zones and trapped water in the crust over a subducting plate. J. Geophys. Res., 93, 12291-13405.

Ho, C. S., 1975: An introduction to the geology of Taiwan: explanatory text of the geologic map of Taiwan, The Ministry of Economic Affairs, Republic of China, 153pp.

Jones, A. G., 1987: MT and reflection: an essential combination. Geophys. J. R. Astr. Soc., 89, 7-18.

Keller, G. V., and F. C. Frischknecht, 1966: Electrical methods in geophysical prospecting. Pergamon Press Inc., 16-19.

Ma, K. F., C. T. Lee, Y. B. Tsai, and T. C. Shin, 1999: The Chi-Chi, Taiwan earthquake: large surface displacements on an island thrust fault. EOS, 80(50), 605-611.

Suppe, J., 1981: Mechanics of mountain building and metamorphism in Taiwan. Mem. Geol. Soc. China, 4, 67-89.

Wu, Y. M., J. K. Chung, T. C. Shin, N. C. Hsiao, Y. B. Tsai, W. H. K. Lee, and T. L.Teng, 1999: Development of an integrated earthquake early warning system in Taiwan - case for the Hualien area earthquakes. TAO, 10, 719-736.

Ward, Stanley H., 1990: Geotechnical and environmental geophysics: review and tutorial (Volume 1), Society of Exploration Geophysicists, Tulsa, Oklahoma, 389 pp.

Yu, S. B., H. Y. Chen, and L. C. Kuo, 1997: Velocity field of GPS stations in the Taiwan area. Tectonophysics, 274, 41-59.

Zhao, D., A. Hasegawa, and S. Horiuchi, 1992: Tomographic imaging of the P-and S-wave velocity structures beneath northeastern Japan. J. Geophys., 97, 19909-19928.

Zhao, D., H. Kanamori, H. Negishi, and D. Wiens, 1996: Tomography of the source area of the 1995 Kobe earthquake: evidence for fluids at the hypocenter? Science, 274, 18911894. 